\title{
Research Article \\ DETERMINATION OF OPTIMUM TEMPERATURE AND PH FOR MYCELIAL GROWTH OF PLEUROTUS SPP I STRAINS
}

\section{BINOY GORAI AND RISHU SHARMA*}

Department of Plant Pathology, Bidhan Chandra Krishi Viswavidyalaya, Mohanpur, West Bengal, 741252, India

*Corresponding Author: Email- rrishu.sharma90@gmail.com

Received: June 20, 2018; Revised: June 26, 2018; Accepted: June 27, 2018; Published: June 30, 2018

\begin{abstract}
Three species of Oyster mushroom viz. Pleurotus ostreatus, Pleurotus sajor-caju, Pleurotus florida were procured from DMR, Solan and a wild strain was collected from Bankura district in West Bengal during the monsoon season of 2017-18. The effect of temperature and pH on mycelial growth of different Pleurotus spp. and a wild collected strain was observed at temperatures $20^{\circ} \mathrm{C}, 25^{\circ} \mathrm{C}, 28^{\circ} \mathrm{C}$ and $32^{\circ} \mathrm{C}$ and pH $4.5,5.5,6.5,7,7.5$ and 8.5 . The study revealed that a temperature of 25 ${ }^{\circ} \mathrm{C}$ was optimum for most of the Pleurotus isolates on PDA plates. Although, the collected strain showed the restricted mycelial growth of $3.20 \mathrm{~cm}$ after 5 and 7 days of inoculation at $28^{\circ} \mathrm{C}$. Also, a pH range of 6.5 to 7.5 was found to be optimum for $P$. ostreatus, $P$. sajor caju and $P$.florida while the wild collected showed optimum mycelial growth at an acidic $\mathrm{pH} 4.5-5.5$ on PDA plates.
\end{abstract}

Keywords- Pleurotus, temperature, $\mathrm{pH}$, mycelia growth, growth inhibition

Citation: Binoy Gorai and Rishu Sharma (2018) Determination of Optimum Temperature and pH for Mycelial Growth of Pleurotus Spp / Strains. International Journal of Microbiology Research, ISSN: 0975-5276 \& E-ISSN: 0975-9174, Volume 10, Issue 6, pp.-1287-1289.

Copyright: Copyright@2018 Binoy Gorai and Rishu Sharma. This is an open-access article distributed under the terms of the Creative Commons Attribution License, which permits unrestricted use, distribution and reproduction in any medium, provided the original author and source are credited.

\section{Introduction}

Pleurotus is generally known as Oyster mushroom all over the world and Dhingri in India [1]. Representatives of genus Pleurotus form a heterogeneous group of edible species of high commercial importance [2]. Mushroom is a fungus which is macro in nature with distinctive fruit body. It can either be epigeous or hypogeous $\mathrm{n}$ can be seen without any eye- aid [3]. It is the most choicest edible mushroom species. Its cultivation started in Germany [4] and with time its cultivation has spread across the globe. This mushroom species are the wood decomposers so can be grown on straw. It has many medicinal properties [5]. It is tough to define the genus Pleurotus due to similarity of morphological traits [20].Studies have demonstrated that Oyster mushrooms are healthy foods, which are low in calories and fat, rich in protein, chitin, vitamins and minerals [6,22]. At present, the annual production of button mushroom is $94676 \mathrm{mt}$ and ranks 1st in India and 2nd is Oyster mushroom with a production of $21272 \mathrm{mt}$. West Bengal rank $6^{\text {th }}$ in Oyster mushroom production in India. Pleurotus spp. are popular and widely cultivated throughout the world $[7,8$,]. In the present study Pleurotus spp. were cultivated under the mushroom house conditions to determine the most efficient substrate, optimum temperature and other growth parameters suitable for high yield under West Bengal climatic conditions. The mushroom production comes out as an excellent alternative to deal with the economic crisis for the family and society. Pleurotus has the capacity to grow under different agro-climates, thus has proved most favorite mushroom by farmers [9]. Pleurotus cultivation was started by [10] In India. Pleurotus ostreatus was the first commercial species. The environmental factors play an important role in the cultivation of Pleurotus spp. It is an exceptional mushroom which contains vital bioactive molecules [21]. The genus Pleurotus possesses divergent temperature requirements. The spread of the mycelium has shown variation under a range of temperatures and $\mathrm{pH}$ on Pleurotus spp. I strains. A few studies have been done in the past where a temperature range of $21-26^{\circ} \mathrm{C}$ was found to be optimal for mycelial growth of Pleurotus ostreatus [11]. The mycellium of spain isolate of $P$. eryngii grew best at $25^{\circ} \mathrm{C}$ and that of Kabul isolate at $20-25^{\circ} \mathrm{C}$ [12].
But, to confirm the optimum temperature and $\mathrm{pH}$ for the mycelial growth of Pleurotus spp. in West Bengal, the present study was carried out to determine the optimum temperature and $\mathrm{pH}$ for the mycelail growth of Pleurotus spp./strains.

\section{Materials and Methods}

The experiment on mushroom (Pleurotus spp.) was conducted in the laboratory of plant Pathology, Faculty of Agriculture, Bidhan Chandra Krishi Viswavidyalaya, Mohanpur, Nadia, West Bengal, India, during the year 2017-2018.

a) Collection, isolation and maintenance of pure culture:

Three species of Oyster mushroom like, Pleurotus ostreatus, Pleurotus sajor-caju, Pleurotus florida mother culture were procured from DMR, Solan (Table 1) and wild strain was collected from Bankura district in West Bengal during the monsoon season of 2017-18 i.e., July-August. Isolations from the fresh specimen, collected from the wild were made following the standard tissue culture technique [13]. Subculturing of the stock cultures was done after a period of 7-10 days on fresh YPDA slants.

b) Effect of temperature on mycelium growth of different Pleurotus spp. with a wild collected strain.

The sterilized petri plate having $9 \mathrm{~cm}$ diameter were filled with PDA medium and then inoculated with $5 \mathrm{~mm}$ mycelium disc form actively growing region of 7 days old culture of each isolates on individual plates. The plates were incubated at temperatures viz. $20^{\circ} \mathrm{C}, 25^{\circ} \mathrm{C}, 28^{\circ} \mathrm{C}$ and $32^{\circ} \mathrm{C}$ growth of mycelium was recorded at 3 days, 5 days and 7 days.

\section{c) Effect of different pH on mycelium growth of different Pleurotus spp and a wild collected strain.}

The experiment was done in PDA by maintaining six different level of $\mathrm{pH}$ which are $4.5,5.5,6.5,7,7.5$ and 8.5 by the use of digital $\mathrm{pH}$ meter. 
The different $\mathrm{pH}$ level was adjusted by adding $\mathrm{HCl}$ and $\mathrm{NaOH}$. Twenty millimeter of PDA having different $\mathrm{pH}$ was dispensed into each petriplates and $5 \mathrm{~mm}$ mycelium disc from actively growing region of 7 days old culture of each isolates was placed in centre of individual petriplates. The petriplates were incubated after inoculation on PDA plates at $25 \pm 2^{\circ} \mathrm{C}$ and growth of mycelium was record at 3 days, 5 days and 7 days respectively.

\section{Results and Discussion \\ i) Collection and culture}

Mycelial cultures of three species of Pleurotus were procured from DMR, Solan and one was collected wild from Bankura district of West Bengal during the monsoon months of 2017-18. Thus, a total of four species/strains were taken for further studies as shown in [Table-1].

Table-1 Procured/ Collected spp./strains of Pleurotus

\begin{tabular}{|l|l|}
\hline Collection from DMR, Solan & Culture/ Species/ Strain \\
\hline P1 & Pleurotus Ostreatus \\
\hline P2 & Pleurotus sajor-caju \\
\hline P3 & Pleurotus florida \\
\hline Collection from DMR, Solan & Culture/ Species/Strain \\
\hline P4 & Unidentified \\
\hline
\end{tabular}

\section{ii)Effect of temperature on mycelial growth}

Mycelial growth pattern of various isolates of Pleurotus was recorded at four different temperatures viz. $20^{\circ}, 25^{\circ}, 28^{\circ}$ and $32^{\circ} \mathrm{C}$ (Fig. 1). A temperature range of $25^{\circ} \mathrm{C}$ was observed to be the optimum for most of the Pleurotus isolates after 3 , 5 and 7 days of inoculation for its mycelia growth on PDA plates [Table-2,3,4]. The study showed that with the increase in temperature, the collected strain showed the restricted mycelial growth after 5 and 7 days of inoculation while at $28^{\circ} \mathrm{C}$, it showed an average diameter of $3.20 \mathrm{~cm}$ with a reduction in growth with advancing days and temperature.
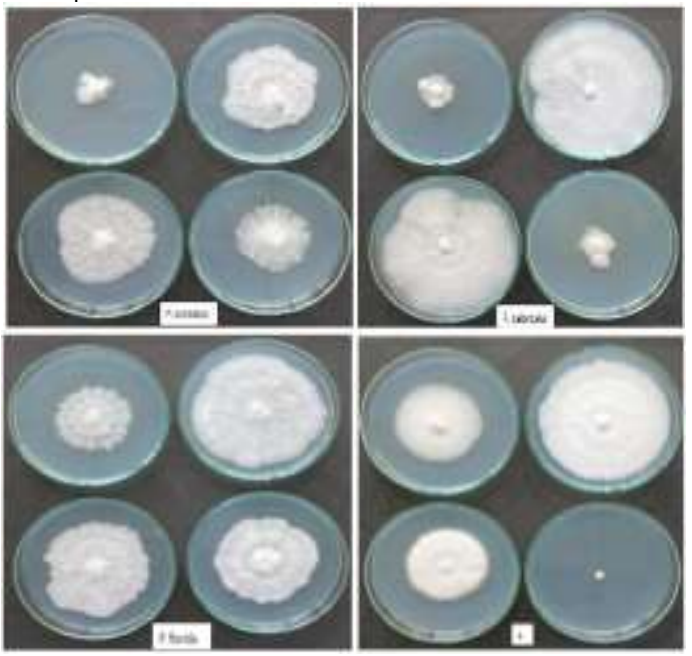

Fig-1A Mycelial growth pattern of P1, P2, P3 and P4 spp./ Strains 7days after Inoculation at different temp

Though, the culture of $P$. sajor-caju showed a higher mycelia growth in comparison rest of the strains/spp. Out of all the procured/ collected Pleurotus spp./strains, whereas $P$. ostreatus exhibited a reduced mycelia growth at $20^{\circ} \mathrm{C}$. Also, the wild collected strain showed an extreme reduced mycelia growth at $32^{\circ} \mathrm{C}$. Similar results were observed by [14] who did an experiment with Pleurotus columbinus and $P$. pulmonarius and found that those species exhibited an optimum growth at a temperature of $25^{\circ} \mathrm{C}$ and a reduction in growth was observed at higher range of temperature i.e., $28-32^{\circ} \mathrm{C}$. $(\mathrm{Fig}-1 \mathrm{~A}, 1 \mathrm{~B})$. The results obtained by [1] are also in congruence to our results in the present study. They also observed an inhibition in growth of Pleurotus spp. at a temperature equal to or greater than $30^{\circ} \mathrm{C}$. Similar optimum temperature has also been reported by several workers [15-17]. [16] studied a temperature range of $25.31^{\circ} \mathrm{C}$ on $P$. flabellatus and concluded that a temperature of $25^{\circ} \mathrm{C}$ is optimum. Mycelial growth type in all the isolates was found to be silky and strandy while the strain P4 showed cottony and thick mycelium. Some of the isolates showed specific zones (P2 and P3).

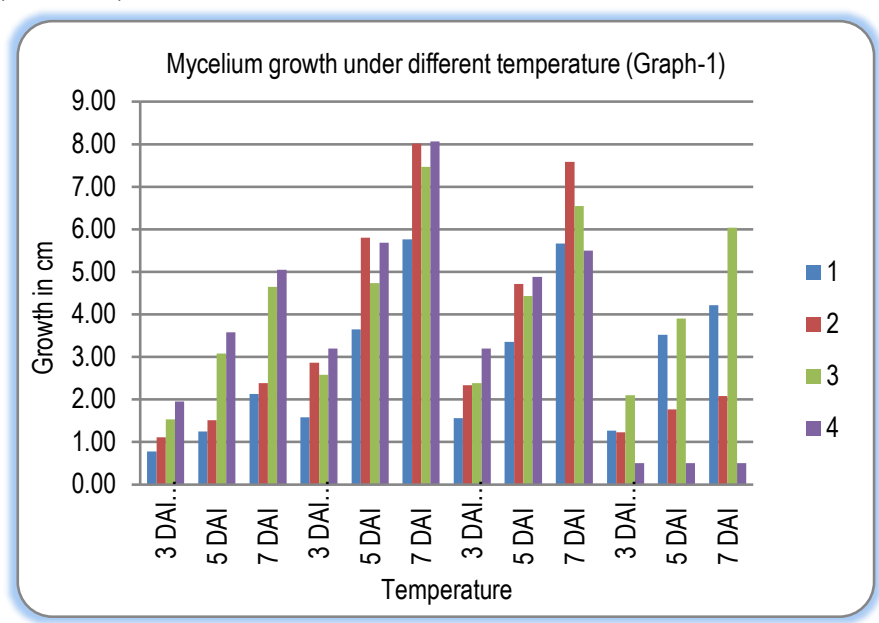

Fig-1B Bar diagram representation mycelial growth of procured/ collected Pleurotus spp under different temperatures

Table-2 Mycelial growth of different Pleurotus spp./strains under different temperatures at 3 Days after inoculation.

\begin{tabular}{|c|l|l|l|l|l|}
\hline \multicolumn{7}{|c|}{ Temperature } \\
\hline Species & $20^{\circ} \mathrm{C}$ & $25^{\circ} \mathrm{C}$ & \multicolumn{1}{|c|}{$28^{\circ} \mathrm{C}$} & $32^{\circ} \mathrm{C}$ & Mean(spp) \\
\hline 1 & 0.78 & 1.58 & 1.57 & 1.27 & 1.30 \\
\hline 2 & 1.12 & 2.87 & 2.33 & 1.23 & 1.89 \\
\hline 3 & 1.53 & 2.58 & 2.38 & 2.10 & 2.15 \\
\hline 4 & 1.95 & 3.20 & 3.20 & 0.50 & 2.21 \\
\hline Mean(temp) & 1.35 & 2.56 & 2.37 & 1.28 & \\
\hline & Spp. & Temp. & SppxTemp. & & \\
\hline SEm \pm & 0.055 & 0.055 & 0.109 & & \\
\hline CD & 0.158 & 0.158 & 0.316 & & \\
\hline
\end{tabular}

Table-3 Mycelial growth of different Pleurotus spp./strains under different temperatures at 5 Days after inoculation.

\begin{tabular}{|c|c|c|c|c|c|}
\hline \multicolumn{6}{|c|}{ Temperature } \\
\hline Species & $20^{\circ} \mathrm{C}$ & $25^{\circ} \mathrm{C}$ & $28^{\circ} \mathrm{C}$ & $32^{\circ} \mathrm{C}$ & Mean(spp) \\
\hline 1 & 1.25 & 3.65 & 3.35 & 3.52 & 2.94 \\
\hline 2 & 1.52 & 5.80 & 4.72 & 1.77 & 3.45 \\
\hline 3 & 3.08 & 4.73 & 4.43 & 3.90 & 4.04 \\
\hline 4 & 3.58 & 5.68 & 4.88 & 0.50 & 3.66 \\
\hline Mean(temp) & 2.36 & 4.97 & 4.35 & 2.42 & \\
\hline & Spp. & Temp. & Spp×Temp. & & \\
\hline SEm \pm & 0.076 & 0.076 & 0.151 & & \\
\hline$C D$ & 0.219 & 0.219 & 0.438 & & \\
\hline
\end{tabular}

Table-4 Mycelial growth of different Pleurotus spp./strains under different temperatures at 7 Days after inoculation.

\begin{tabular}{|l|l|l|l|l|l|}
\hline \multicolumn{5}{|c|}{ Temperature } \\
\hline Species & $20^{\circ} \mathrm{C}$ & $25^{\circ} \mathrm{C}$ & $28^{\circ} \mathrm{C}$ & $32^{\circ} \mathrm{C}$ & Mean(spp) \\
\hline 1 & 2.13 & 5.77 & 5.67 & 4.22 & 4.45 \\
\hline 2 & 2.38 & 8.02 & 7.58 & 2.08 & 5.02 \\
\hline 3 & 4.65 & 7.47 & 6.55 & 6.04 & 6.18 \\
\hline 4 & 5.05 & 8.07 & 5.5 & 0.5 & 4.78 \\
\hline Mean(temp) & 3.55 & 7.33 & 6.33 & 3.21 & \\
\hline & Spp. & Temp. & SppxTemp. & & \\
\hline SEm \pm & 0.115 & 0.115 & 0.23 & & \\
\hline CD & 0.332 & 0.332 & 0.665 & & \\
\hline & & & & & \\
\hline
\end{tabular}

\section{iii) Effect of $\mathrm{pH}$ on mycelial growth}

Mycelial growth pattern of various isolates of Pleurotus spp was recorded at six different $\mathrm{pH}, 4.5,5.5,6.5,7,7.5$ and 8.5 four different temperatures viz., (Fig. $2 A, B, C, D) .7$ days of after inoculation, $\mathrm{pH}$ range of temperature 6.5 to 7.5 was found to be optimum for $P$. ostreatus, $P$. sajor caju and $P$.florida while the wild collected showed optimum mycelia growth at an acidic $\mathrm{pH} 4.5-5.5$ on PDA plates. 
The study showed that with the increase in pH upto 8.5, the Pleurotus spp showed inhibited mycelia growth after going down from $\mathrm{pH}$ 7.0. (Fig-2E). Similar, results were given by [18] who observed that an initial $\mathrm{pH}$ of 6.4 and 6.2 is optimum for cultivation of $P$. florida and $P$. citrinoplieatus in submerged culture. The studies by various workers $[19,14]$ has revealed that a $\mathrm{pH}$ of $6.5-7.5$ is optimum for the growth of Pleurotus spp which is in congurance to our obtained results. Mycelial growth type in all the isolates was found to be silky and strandy while the strain P4 showed cottony and thick mycelium which also showed no growth at $32^{\circ} \mathrm{C}$. Some of the isolates showed specific zones (P2 and P3).

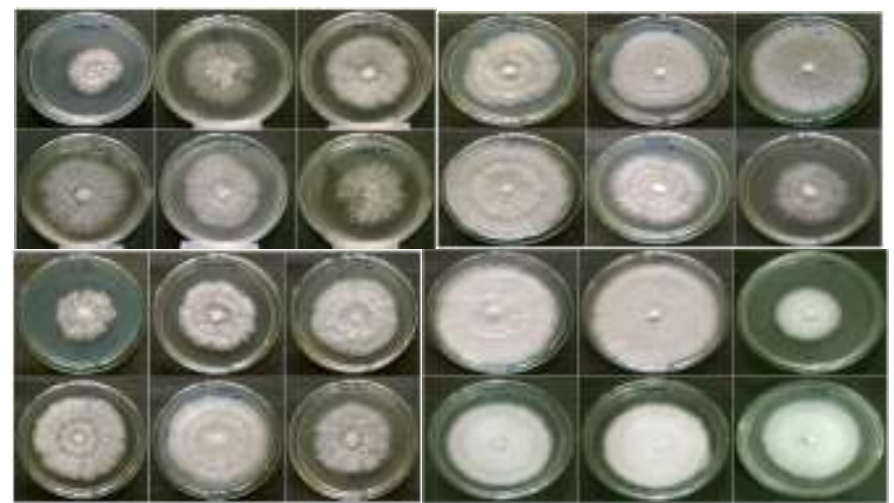

Fig-2A, 2B, 2C, 2D: Mycelial growth pattern of P1, P2, P3 and P4 after 7 days of inoculation at different $\mathrm{pH}$

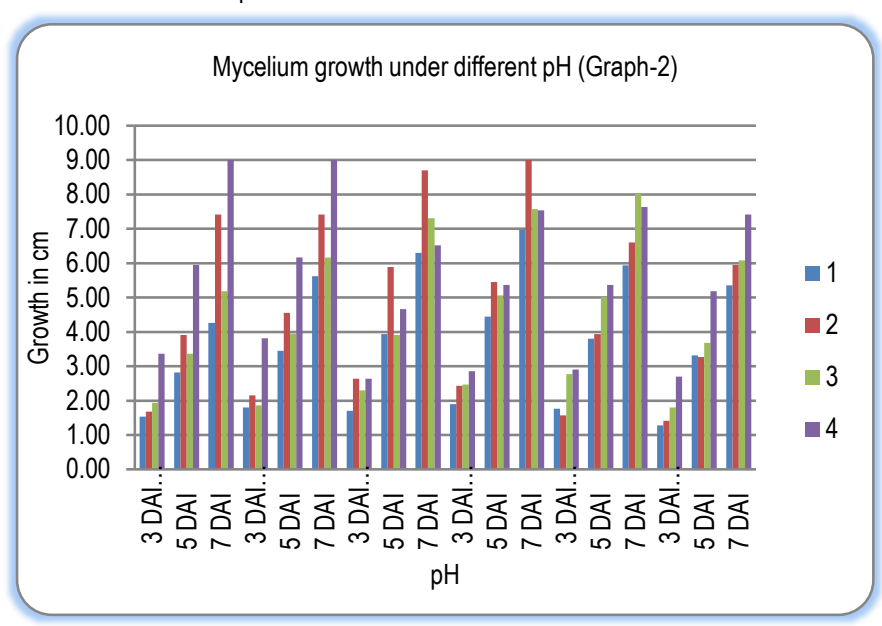

Fig-2E Bar diagram representing mycelial growth of procured/ collected Pleurotus spp under different $\mathrm{pH}$

\section{Conclusion}

The effect of temperature on mycelial growth of different Pleurotus spp. and a wild collected strain was observed at temperatures $20^{\circ}, 25^{\circ}, 28^{\circ}$ and $32^{\circ} \mathrm{C}$ which revealed that a temperature range of $25^{\circ} \mathrm{C}$ was optimum for most of the Pleurotus isolates on PDA plates. The study showed that with the increase in temperature, the collected strain showed the restricted mycelial growth after 5 and 7 days of inoculation while at $28^{\circ} \mathrm{C}$, it showed an average diameter of $3.20 \mathrm{~cm}$ with a reduction in growth. Also, the effect of $\mathrm{pH}$ on mycelial growth of various isolates of Pleurotus spp was recorded at six different $\mathrm{pH} 4.5,5.5,6.5,7,7.5$ and $8.5 \mathrm{pH}$ after 7 days after inoculation, a pH range of 6.5 to 7.5 was found to be optimum for $P$. ostreatus, $P$. sajor caju and P.florida while the wild collected showed optimum mycelial growth at an acidic pH 4.5-5.5 on PDA plates. The study showed that with the increase in $\mathrm{pH}$ upto 8.5, the Pleurotus spp showed inhibited mycelial growth after $\mathrm{pH}$ 7.0.

Application of research: The determination of optimum temperature and $\mathrm{pH}$ for Pleurotus spp./starins could be used for commercial as well as at farmer's level without using much resources and thus saving the time and money. Also, the suitable spp. can be grown according to the environment. In future, it can be linked to other small units and can be abe source of regular income to farmers by cultivation at suitable time of the year.

Research Category: Plant Pathology

Acknowledgment / Funding: Author thankful to Bidhan Chandra Krishi Viswavidyalaya, Mohanpur, West Bengal, 741252, India. Author also thankful to ICAR-AICRP- Mushroom.

*Research Guide or Chairperson of research: Rishu Sharma

University: Bidhan Chandra Krishi Viswavidyalaya, Mohanpur, 741252

Research project name or number: MSc Thesis

\section{Author Contributions: All author contributed equally}

Author statement: All authors read, reviewed, agree and approved the final manuscript

\section{Conflict of Interest: None declared}

Ethical approval: This article does not contain any studies with human participants or animals performed by any of the authors.

\section{References}

[1] Lovkesh Beniwal J. and Pahil V.S. (2006) Crop Research Hisar. 32(3), 499-503.

[2] Zervakis G. I., Monslavo J. M. and Vilgalys R. (2004) Microbiology 150,715-726.

[3] Chang S.T., Lau O. W. and Cho K. Y. (1981) European Journal of Applied Microbiology and Biotechnology, 12, 58-62.

[4] Flack R. (1917) Z. forst-sagdwes, 49,159-165.

[5] Patel Y., Naraian R. and Singh V.K. (2012) World Journal of Fungal and Plant Biology, 3(1), 01-12.

[6] Manzi P., Gambelli L., Marconi S., Vivanti V. and Pizzoferrato L. (1999) Food Chem., 65, 477-482.

[7] Shah Z.A., Ashraf M., Ishtiaq M.C. (2004) Pak J Nutr., 3,158-160.

[8] Flores C. (2006) East West Management Institute, New York.

[9] Zardazil F. and Kurtzman Jr. R. H (1984) The Chinese University Press, HongKong, 227-298.

[10] Bano Z. and Srivastava H.C (1962) Food Science, 11, 36-38.

[11] Block S. S., Tsao G. and Han L. (1959) Mushroom Science 4, 309325.

[12] Sharma A.D. and Jandaik C.L. (1984) 10(1), 20-26.

[13] Gamborg 0.L. (2002) In Vitro Cellular \& Developmental Biology, 38(2), 84-92.

[14] El Fallal A. A, El Dein M.M.N. and Khalil A.E. (2003) Egyptian Journal of Microbiology, 38(1), 27-38.

[15] Namdeo J.K., Thakur M.P., Shukla C.S. and Thrimurty V.S. (2002) National Symposium on Perspectives in Integrated Plant Disease Management held at Nagpur, February 13-14, 48.

[16] Wei S.H., Jie Y.Y., Rong H.L., Li H.L. and Yan M.G. (2004) Edible fungi of China 23 (2), 29-30.

[17] Kashangura, C., Hallsworth J.E. and Mswaka, A.Y. (2006) Mycological Research 11(3), 312-317.

[18] Khan M. W., Ali M. A., Khan N. A., Khan M. A., Rehman R. and Javed, N. (2013) Pakistan-Journal of Botany, 45(1), 297-302.

[19] Mukherjee and Senguota (1986) Applied and Environmental Microbiology, 52, 1412-1414.

[20] Shnyreva A.A. and Shnyreva A. V. (2015) Russian Journal of Genetics, 51 (2), 148-157.

[21] Girmay Z., Gorems W., Birhanu G. and Zewdie S. (2016) AMB Express, 6, 87.

[22] Tolera Kumela D. and Solomon Abera (2017) Food Science \& Nutrition 5.5, 989-996. 